\title{
Sulforaphane promotes immune responses in a WEHI-3-induced leukemia mouse model through enhanced phagocytosis of macrophages and natural killer cell activities in vivo
}

\author{
YUNG-LUEN SHIH ${ }^{1-3 *}$, LUNG-YUAN WU ${ }^{4 *}$, CHING-HSIAO LEE ${ }^{5}$, YUNG-LIANG CHEN ${ }^{6}$, \\ SHU-CHING HSUEH ${ }^{7}$, HSU-FENG LU ${ }^{7,8}$, NIEN-CHIEH LIAO ${ }^{5,7}$ and JING-GUNG CHUNG ${ }^{9,10}$ \\ ${ }^{1}$ Department of Pathology and Laboratory Medicine, Shin Kong Wu Ho-Su Memorial Hospital, Shihlin, Taipei 11101; \\ ${ }^{2}$ School of Medical Laboratory Science and Biotechnology, Taipei Medical University, Xinyi, Taipei 110; \\ ${ }^{3}$ School of Medicine, College of Medicine, Fu-Jen Catholic University, Xinzhuang, New Taipei 242; \\ ${ }^{4}$ School of Chinese Medicine for Post Baccalaureate, I-Shou University, Yanchao, Kaohsiung 824; \\ ${ }^{5}$ Department of Medical Technology, Jen-Teh Junior College of Medicine, Nursing and Management, Houlong, Miaoli 360; \\ ${ }^{6}$ Department of Medical Laboratory Science and Biotechnology, Yuanpei University, Xiangshan, Hsinchu 30015; \\ ${ }^{7}$ Department of Clinical Pathology, Cheng Hsin General Hospital, Beitou, Taipei 112; \\ ${ }^{8}$ Restaurant, Hotel and Institutional Management, Fu-Jen Catholic University, Xinzhuang, New Taipei 242; \\ ${ }^{9}$ Department of Biological Science and Technology, China Medical University, Wufeng, Taichung 404; \\ ${ }^{10}$ Department of Biotechnology, Asia University, Wufeng, Taichung 413, Taiwan, R.O.C.
}

Received May 18,2015; Accepted January 26, 2016

DOI: $10.3892 / \mathrm{mmr} .2016 .5028$

\begin{abstract}
Sulforaphane (SFN) is an isothiocyanate, inducing cytotoxic effects in various human cancer cells, including leukemia cells through cell cycle arrest and apoptosis. However, the effect of SFN on the immune responses in a leukemia mouse model remains to be investigated. The present study investigated whether SFN has an effect on the immune responses in a WEHI-3-induced leukemia mouse model in vivo. Normal BALB/c mice were injected with WEHI-3 cells to generate the leukemia mouse model, and were subsequently treated with placebo or SFN $(0,285,570$ and $1,140 \mathrm{mg} / \mathrm{kg})$ for 3 weeks. Following treatment, all mice were weighted and blood samples were collected. In addition, liver and spleen samples were isolated to determine cell markers, phagocytosis
\end{abstract}

Correspondence to: Professor Jing-Gung Chung, Department of Biological Science and Technology, China Medical University, 91 Xueshi Road, North District, Wufeng, Taichung 404, Taiwan, R.O.C.

E-mail: jgchung@mail.cmu.edu.tw

Dr Nien-Chieh Liao, Department of Clinical Pathology, Cheng Hsin General Hospital, 45 Cheng Hsin Street, Beitou, Taipei 112, Taiwan, R.O.C.

E-mail: ch1835@chgh.org.tw

*Contributed equally

Key words: sulforaphane, WEHI-3-induced leukemia mouse model, phagocytosis, macrophage and natural killer (NK) cell activities, and cell proliferation was examined using flow cytometry. The results indicated that SFN treatment had no significant effect on the spleen weight, however it decreased liver and body weight. Furthermore, SFN treatment increased the percentage levels of CD3 ( $\mathrm{T}$ cells) and CD19 (B cell maker), however had no effect on the levels of CD11b (monocytes) or Mac-3 (macrophages), compared with the WEHI-3 control groups. The administration of SFN increased the phagocytosis of macrophages from peripheral blood mononuclear cells and peritoneal cavity, and increased the activity of NK cells from splenocytes. Administration of SFN promoted $\mathrm{T}$ and $\mathrm{B}$ cell proliferation following stimulation with concanavalin A and lipopolysaccharide, respectively.

\section{Introduction}

Leukemia is a malignant neoplasm (unregulated proliferation of immature blood cells) and originates in the bone marrow and/or mutant hematopoietic stem cells (1). The neoplastic cells move into the blood, accumulating in large numbers causing the clinical disease in patients (2). Leukemias, including acute myeloid, B-lymphoblastic, T-lymphoblastic and leukemias of ambiguous lineage, are well documented in patients (3). Thus far, the primary treatment for patients with leukemia is chemotherapy, which induces a complete remission and is consolidated with further cycles of treatment (4). However, chemotherapy has relatively low efficacy and high toxicity in patients with leukemia (4). Therefore, the treatment of leukemia remains a therapeutic challenge, and the identification and development of novel biomarkers is required.

Isothiocyanates are present in a variety of cruciferous vegetables and have biological activity, including 
anticarcinogenic activity (5-8). Sulforaphane (SFN) is an isothiocyanate and effectively inhibits chemically-induced tumors in rodents $(9,10)$ by inducing the phase II detoxification enzymes (11). A previous study demonstrated the cell cycle specificity of SFN mediated apoptosis in Jurkat T-leukemia cells (12). Another previous study indicated that the generation of cellular reactive oxygen species (ROS) serves a pivotal role in the initiation of SFN-triggered apoptosis in the U937 cells (13). In addition, SFN induces cytodifferentiation in granulocytic and macrophagic lineage, and resulted in a significant increase in the apoptotic cell fraction (14). A previous study demonstrated that SFN suppresses the tumor necrosis factor- $\alpha$-mediated activation of nuclear factor- $\kappa \mathrm{B}$ and induces apoptosis through the activation of ROS-dependent caspase-3 in human leukemia cells (15). Furthermore, SFN acts as an adjunctive agent to improve the therapeutic response in high-risk patients with acute lymphoblastic leukemia and activated Akt signaling (16). A previous study demonstrated that SFN may be a novel therapeutic agent, protecting against malignancies, and further research on SFN is required in a wider population of patients with leukemia (17).

A previous study indicated that natural compounds and crude extract of natural plants promotes immune responses in leukemia mice (18-20). To the best of our knowledge, no previous study has demonstrated that SFN may have an effect on the immune responses in leukemia mice in vivo. Therefore, in the present study, the effect of SFN on the immune responses in leukemia BALB/c mice in vivo was investigated. The results of the present study demonstrated that SFN promoted immune responses, including increasing the macrophage phagocytosis and natural killer (NK) cell activities in leukemia BALB/c mice.

\section{Materials and methods}

Materials and reagents. SFN and dimethyl sulfoxide (DMSO) were purchased from Sigma-Aldrich (St. Louis, MO, USA). Tissue culture plastics were obtained from BD Biosciences (San Jose, CA, USA). Gibco RPMI-1640 medium, fetal bovine serum (FBS), L-glutamine and penicillin/streptomycin were obtained from Thermo Fisher Scientific, Inc. (Waltham, MA, USA). Antibodies against CD3, CD19, CD11b and Mac-3 were obtained from BD Biosciences (BD Pharmingen; San Diego, CA, USA). SFN was dissolved in DMSO at $1 \%$ stock solution and was maintained at $-20^{\circ} \mathrm{C}$ in a $50 \mathrm{ml}$ tube, in the dark.

Murine WEHI-3 leukemia cells. Murine WEHI-3 myelomonocytic leukemia cells were obtained from the Food Industry Research and Development Institute (Hsinchu, Taiwan, ROC). The cells were maintained in RPMI-1640 medium, supplemented with $10 \% \mathrm{FBS}, 100$ units $/ \mathrm{ml}$ penicillin, $100 \mu \mathrm{g} / \mathrm{ml}$ streptomycin and $2 \mathrm{mM} \mathrm{L-glutamine}$ at $37^{\circ} \mathrm{C}$ with $5 \% \mathrm{CO}_{2}$ in a humidified incubator, as previously described (18-20).

Male BALB/c mice and SFN treatment. Male BALB/c mice ( $\mathrm{n}=50$; age, 4-weeks-old; weight, $\sim 22-25 \mathrm{~g}$ ) were obtained from the National Laboratory Animal Center (Taipei, Taiwan, ROC). The mice were maintained on $12 \mathrm{~h}$ light/dark cycles at $25^{\circ} \mathrm{C}$ in the animal center of China Medical University
(Taichung, Taiwan, ROC). Animal experiments were reviewed and approved by the Institutional Animal Care and Use Committee of China Medical University (approval ID: 101-238-C). All animals were cared for according to the institutional animal ethical guidelines of the China Medical University, as previously described (18). The mice were randomly divided into five groups ( $n=10 /$ group), and for groups II-IV, the mice were peritoneally inoculated with $1 \times 10^{6}$ WEHI-3 leukemia cells to generate a leukemia model. The groups were divided and separated as follows: Group I, mice were fed a normal diet as control; group II, mice were fed a normal diet as positive control; group III-V, mice were treated with 285,570 or $1,140 \mathrm{mg} / \mathrm{kg}$ SFN in olive oil, respectively. SFN in olive oil was administered by gavage for 20 days and the body weight was recorded. At the end of treatment, all mice were weighed and sacrificed by euthanasia with $\mathrm{CO}_{2}$, as previously described (18-20).

Immunofluorescence staining for surface markers in isolated white blood cells. Following treatment, mice from each group were individually weighted and blood samples were collected. The liver and spleen were individually collected and splenocytes were isolated to measure the activity of NK cells, as previously described (18). Cell markers in isolated leukocytes were measured. Briefly, $1 \mathrm{ml}$ blood was collected, lysed with 1X Pharm Lyse lysing buffer (BD Biosciences) to destroy red blood cells, according to the manufacturer's protocol, and the leukocytes were collected. Isolated leukocytes were stained with fluorescein isothiocyanate (FITC)-conjugated monoclonal hamster anti-mouse CD3 (cat. no. 553062; 1:10), phycoerythrin PE-conjugated monoclonal rat anti-mouse CD19 (cat. no. 553786; 1:20), FITC-conjugated monoclonal rat anti-mouse CD11b (cat. no. 553310; 1:20) and PE-conjugated rat monoclonal anti-mouse Mac-3 (cat. no. 553324; 1:20) primary antibodies for $30 \mathrm{~min}$ at room temperature, and were subsequently washed three times with phosphate-buffered saline. Following washing, the leukocytes were stained with secondary antibody and the percentage of cell markers was determined using flow cytometer (FACS Calibur; BD Biosciences), the data was analyzed using Cell Quest Pro (version 5.2.1; BD Biosciences), as previously described (18-20).

Measurement of phagocytotic macrophages. Following treatment, macrophages were isolated from the peripheral blood mononuclear cells (PBMC) and the peritoneum, as previously described (18-20), and phagocytosis was determined using the PHAGOTEST kit (Orpegen Pharma GmbH, Heidelberg, Germany). Briefly, isolated macrophages were placed in plates and $50 \mu 1$ Escherichia coli-FITC was added to the cells, according to the manufacturer's protocol. The samples were subsequently analyzed for phagocytosis by flow cytometry and were quantified using the Becton Dickinson CellQuest software (BD Biosciences), as previously described (18-20).

Measurement of NK cell cytotoxic activity. Following treatment, splenocytes were isolated and placed into a 96-well plate $\left(1 \times 10^{5}\right.$ cells/well), with $1 \mathrm{ml}$ RPMI-1640 medium. YAC-1 cells $\left(2.5 \times 10^{7}\right.$ cells $)$ and PKH-67/Dil.C buffer (Sigma-Aldrich) were added to the cells, according to 
A

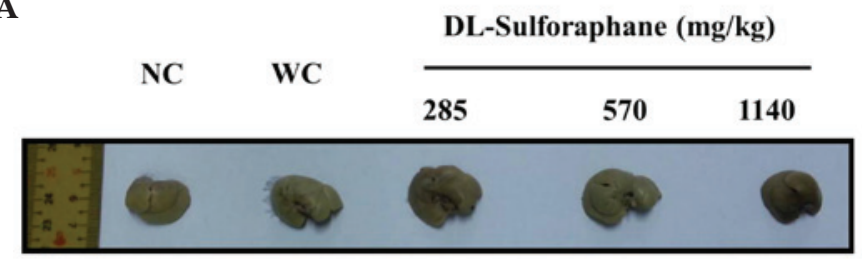

B
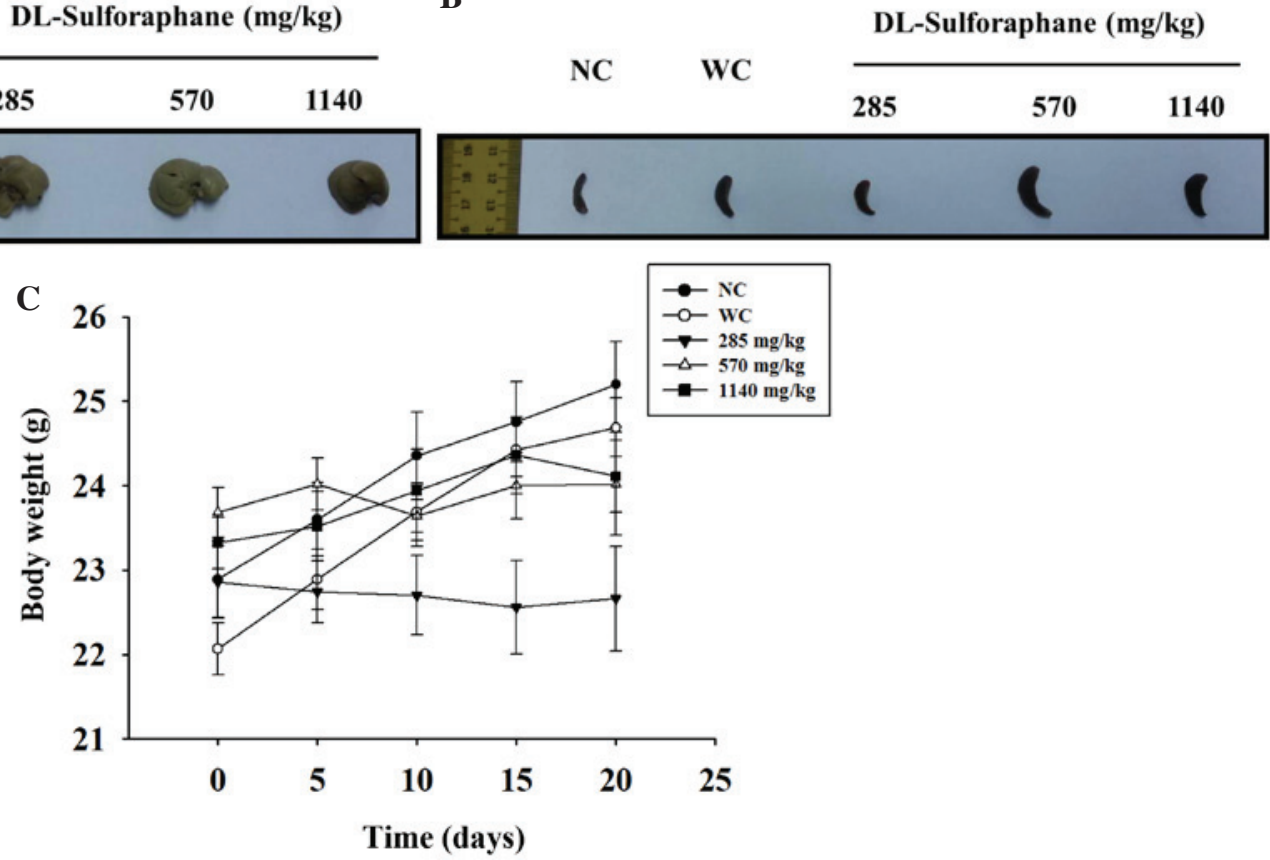

D

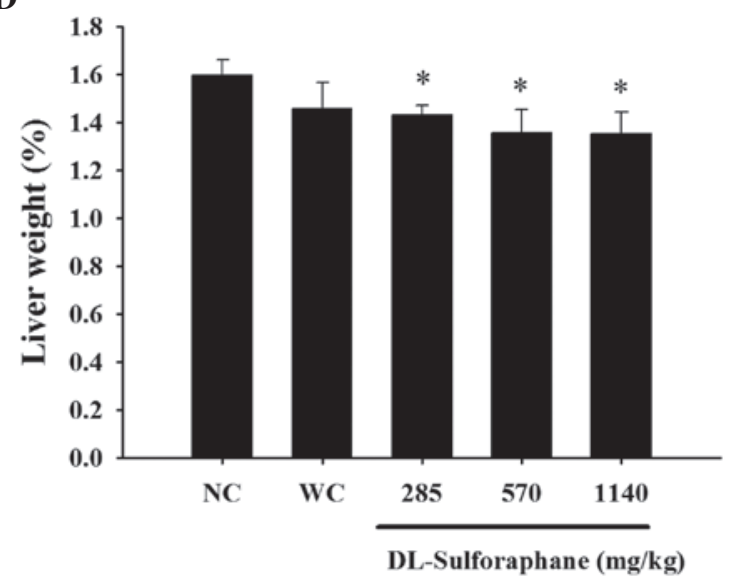

$\mathbf{E}$

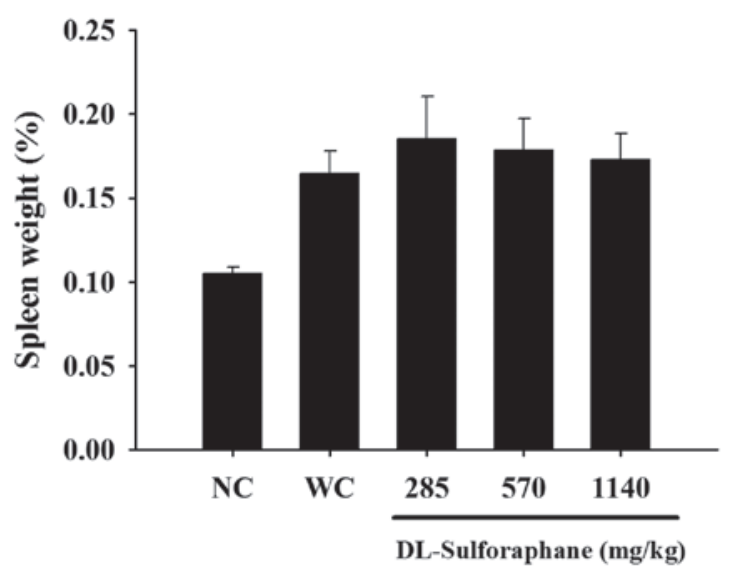

Figure 1. Effect of sulforaphane on body, liver and spleen weights in non-leukemic untreated mice and leukemic untreated, $285,570 \mathrm{or} 1140 \mathrm{mg} / \mathrm{kg}$ sulforaphane-treated mice. All animals were treated for 20 days. Representative images of (A) liver and (B) spleen. (C) Body, (D) liver and (E) spleen weights were determined. Data are presented as mean \pm standard deviation. ${ }^{*} \mathrm{P}<0.05$ vs the WC group. The total body weights were measured every 5 days. NC, normal control; WC, WEHI-3-induced leukemia control.

the manufacturer's protocol, and were mixed thoroughly for $2 \mathrm{~min}$ at $25^{\circ} \mathrm{C}$. PBS $(2 \mathrm{ml})$ was added to the wells for $1 \mathrm{~min}$, followed by $4 \mathrm{ml}$ medium for $10 \mathrm{~min}$. Following the incubation, the cells were centrifuged for $2 \mathrm{~min}$ at $25^{\circ} \mathrm{C}$ and $290 \mathrm{x}$ g, and the NK cell cytotoxic activity was measured using flow cytometry, as previously described (18-20).

Measurement of $T$ and $B$ cell proliferation. Isolated splenocytes were seeded into 96 -well plates $\left(1 \times 10^{5}\right.$ cells/well) with $100 \mu$ l RPMI-1640 medium. To measure T cell proliferation, concanavalin A (Con A; $5 \mu \mathrm{g} / \mathrm{ml}$ ) was added to the cells for a 3-day stimulation. To measure B cell proliferation, lipopolysaccharide (LPS; $5 \mu \mathrm{g} / \mathrm{ml}$ ) was added to the cells for a 5-day stimulation. Following this stimulation, proliferation was determined using the CellTiter 96 AQueous One Solution Cell Proliferation Assay kit (Promega Corporation, Madison, WI, USA), as previously described (18-20).
Statistical analysis. The data are expressed as the mean \pm standard deviation. All experiments were repeated a minimum of three times. The association between the control and SFN-treated groups was analyzed using the Student's t-test in Sigmaplot (version 12.0; Systat Software, Inc., San Jose, CA, USA). $\mathrm{P}<0.05$ was considered to indicate a statistically significant difference.

\section{Results}

SFN treatment influences body, liver and spleen weights in leukemic mice. In accordance with the in vivo protocol, normal and WEHI-3 cells generating leukemic mice were divided into five groups: Normal control, untreated; leukemic positive control, untreated; and leukemic mice treated with SFN at various doses for 20 days. The representative liver and spleen images are demonstrated in Fig. 1A and B, and the body, liver 
A

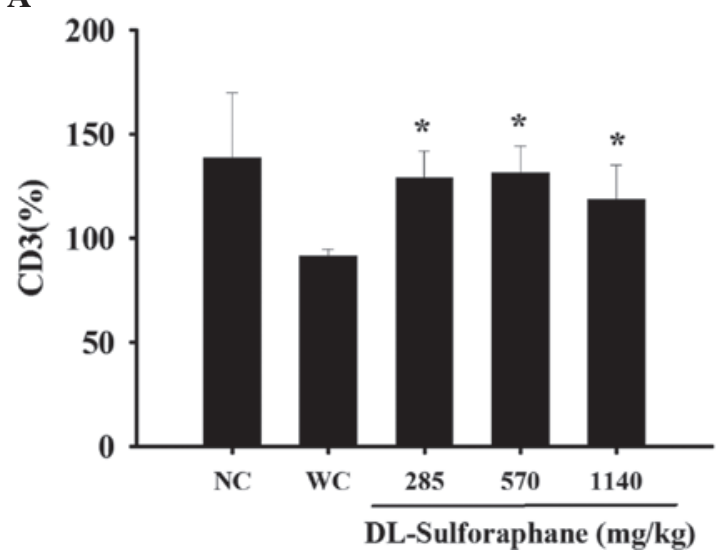

C

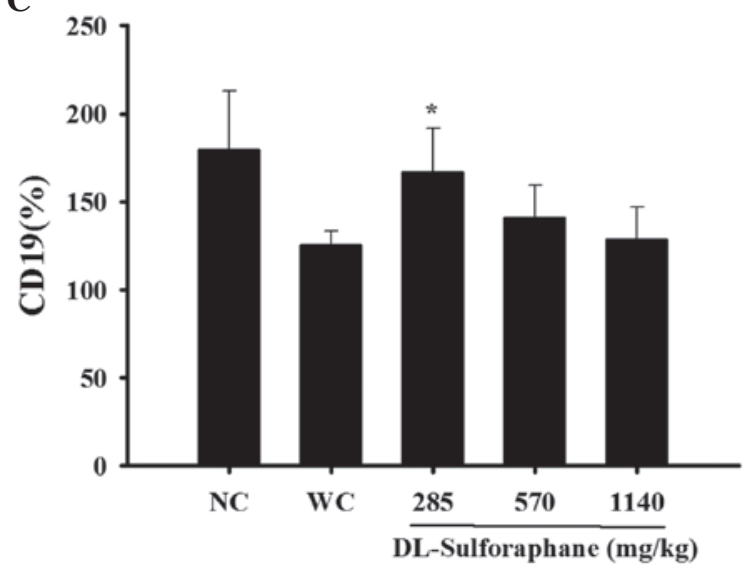

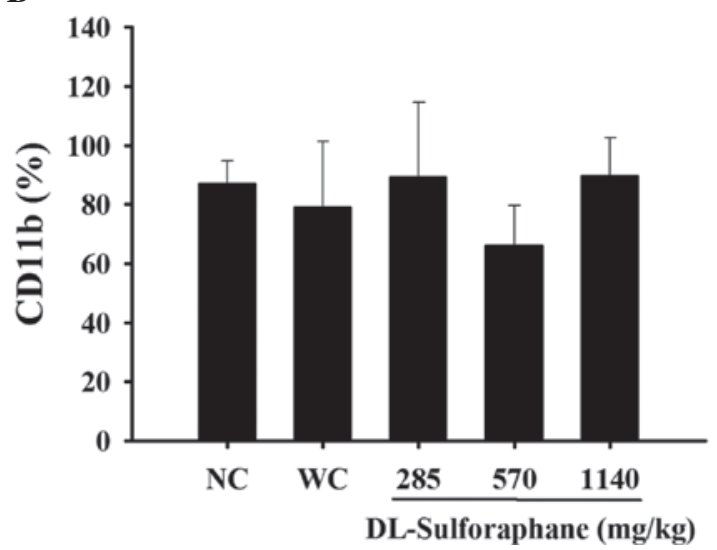

D

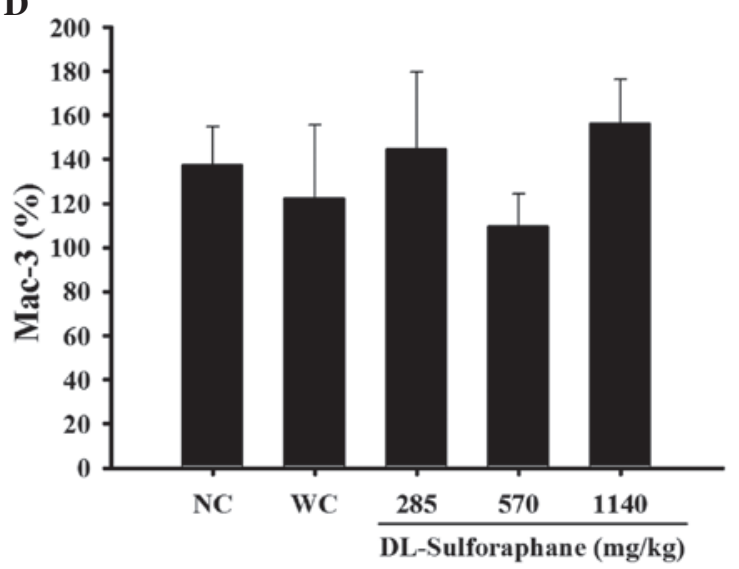

Figure 2. Effect of sulforaphane treatment on the levels of cell markers in white blood cells from non-leukemic untreated mice, and leukemic untreated, 285, 570 or $1140 \mathrm{mg} / \mathrm{kg}$ sulforaphane-treated mice. Blood samples were collected from each group (n=10) and analyzed for (A) CD3, (B) CD19, (C) CD11b and (D) Mac-3. The data are expressed as the mean \pm standard deviation ( $\mathrm{n}=3$; * $\mathrm{P}<0.05$ vs. the control groups). NC, normal control; WC, WEHI-3-induced leukemia control; CD, cluster of differentiation; Mac, macrophage antigen.

and spleen weights are shown in Fig. 1C-E, respectively. These results indicated that SFN had no significant effect on the body and spleen weights (Fig. 1C and E), with the exception that a low dose $(285 \mathrm{mg} / \mathrm{kg}$ of SFN) decreased the body weight when compared with the untreated leukemic mice, as shown in Fig. 1B.

SFN treatment influences cell markers in the white blood cells of leukemic mice. Blood samples were collected to measure the levels CD3, CD19, CD11b and Mac-3 cell markers using flow cytometry. As demonstrated in Fig. 2A, SFN $(285,570$ or $1,140 \mathrm{mg} / \mathrm{kg})$ treatment significantly promoted the percentage levels of CD3 compared with the control groups $(\mathrm{P}<0.05)$. Furthermore, SFN $(285 \mathrm{mg} / \mathrm{kg})$ treatment significantly promoted the percentage of levels CD119 $(\mathrm{P}<0.05$; Fig. 2B), however had no significant effect on the levels of CD11b (Fig. 2C) and Mac-3 (Fig. 2D), compared with the control groups.

SFN treatment effects the phagocytotic activity of macrophages from the PBMC and peritoneal cavity of leukemic mice. Cells were isolated from PBMC and peritoneal cavity following treatment to determine the levels of phagocytosis using flow cytometry. As demonstrated in Fig. 3A, $285 \mathrm{mg} / \mathrm{kg}$ SFN treatment significantly increased the phagocytotic activity of macrophages from PBMC compared with the WEHI-3 control group $(\mathrm{P}<0.05)$. In addition, 285, 570 and 1,140 $\mathrm{mg} / \mathrm{kg} \mathrm{SFN}$ treatment significantly decreased the phagocytotic activity of macrophages from the peritoneal cavity compared with the normal control group $(\mathrm{P}<0.05 ;$ Fig. 3B).

SNF treatment influences the cytotoxic activity of NK cells from leukemic mice. Splenocytes were isolated from the leukemic mice and were used at different ratios as NK effector cells in cytolytic assays against YAC-1 target cells. The NK activity was measured by flow cytometry and the results indicated that YAC-1 cells were killed by NK cells following treatment with 285,570 or $1,140 \mathrm{mg} / \mathrm{kg} \mathrm{SFN}$, when compared with the untreated leukemic mice (Fig. 4).

SFN treatment has an effect on $B$ and $T$ cell proliferation in leukemic mice. To assess any differences in the proliferative capacity of T and B cells following SFN treatment, isolated cells from the spleen of each mouse were cultured and stimulated with Con A and LPS, respectively. As demonstrated in Fig. 5A, treatment with $1,140 \mathrm{mg} / \mathrm{kg}$ SFN led to a marked increase of B cell proliferation compared with the control groups. However, treatment with 285,570 or $1,140 \mathrm{mg} / \mathrm{kg} \mathrm{SFN}$ resulted in a marked increase of $\mathrm{T}$ cell proliferation compared with the control groups (Fig. 5B). 
A

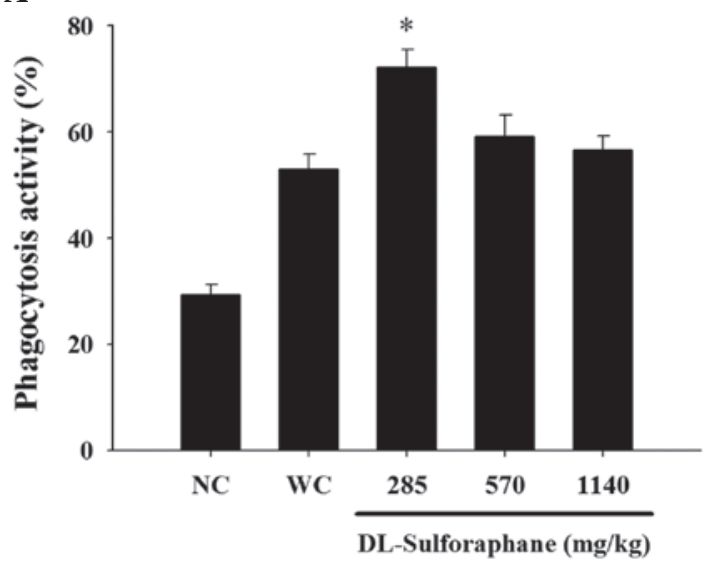

B

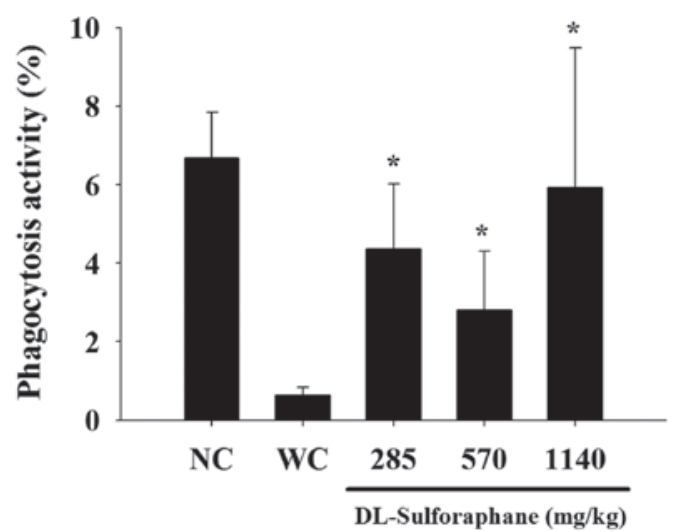

Figure 3. Effect of sulforaphane treatment on the phagocytotic activity of macrophages from PBMC and peritoneal cavity in non-leukemic untreated mice, and leukemic untreated, 285,570 or $1140 \mathrm{mg} / \mathrm{kg}$ sulforaphane-treated mice. Blood samples were collected from each group ( $\mathrm{n}=10)$ and macrophages were isolated from the (A) PBMCs and (B) peritoneum of each mouse. Data are presented as mean \pm standard deviation. " $\mathrm{P}<0.05$, vs WC control group. NC, normal control; WC, WEHI-3-induced leukemia control; PBMC, peripheral blood mononuclear cell.

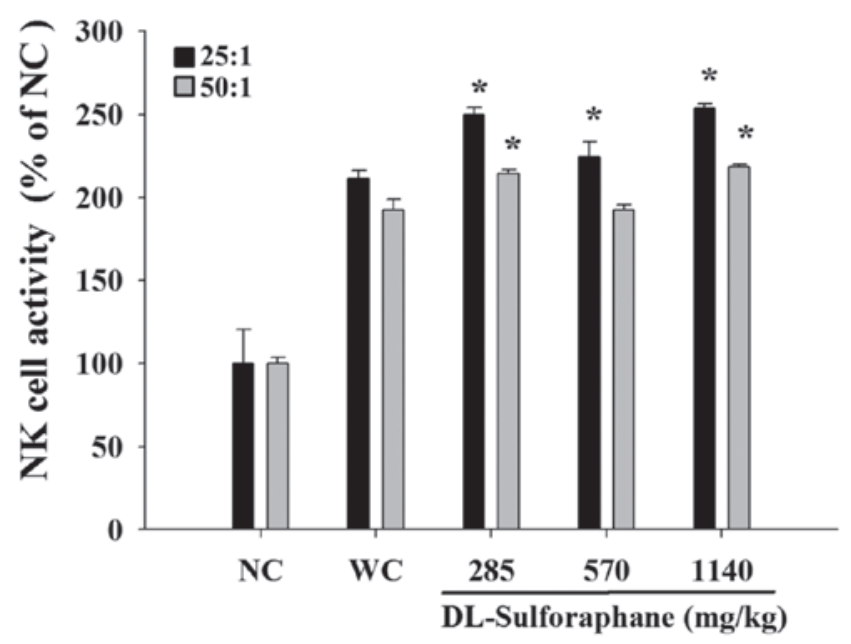

Figure 4. Effect of sulforaphane treatment on the cytotoxic activity of NK cells in non-leukemic untreated mice, and leukemic untreated, 285,570 or $1140 \mathrm{mg} / \mathrm{kg}$ sulforaphane-treated mice. Isolated splenocytes were placed in $1 \mathrm{ml}$ RPMI-1640 medium in 96-well plates. Target YAC-1 cells with serum-free RPMI-1640 medium and the PKH-67/Dil.C buffer were added to the cells. NK cell cytotoxic activity was measured by flow cytometry. Data are presented as mean \pm standdard deviation. ${ }^{*} \mathrm{P}<0.05$ vs WC control group). NK, natural killer; NC, normal control; WC, WEHI-3-induced leukemia control.

\section{Discussion}

In the present study, murine WEHI-3 cells were utilized to generate leukemic mice. The mice were randomly divided into different groups for oral SFN treatment at various concentrations. Following treatment, blood samples were collected from the mice for cell marker analysis and measurement of phagocytotic activity in macrophages. In addition, splenocytes were isolated to assess the NK cell activity, and the proliferation of $\mathrm{T}$ and $\mathrm{B}$ cells. The results of the present study indicated that SFN treatment had no significant effect on body and spleen weights (Fig. 1C and E), however $280 \mathrm{mg} / \mathrm{kg}$ SFN resulted in reduced body weights (Fig. 1C) when compared with the control
A

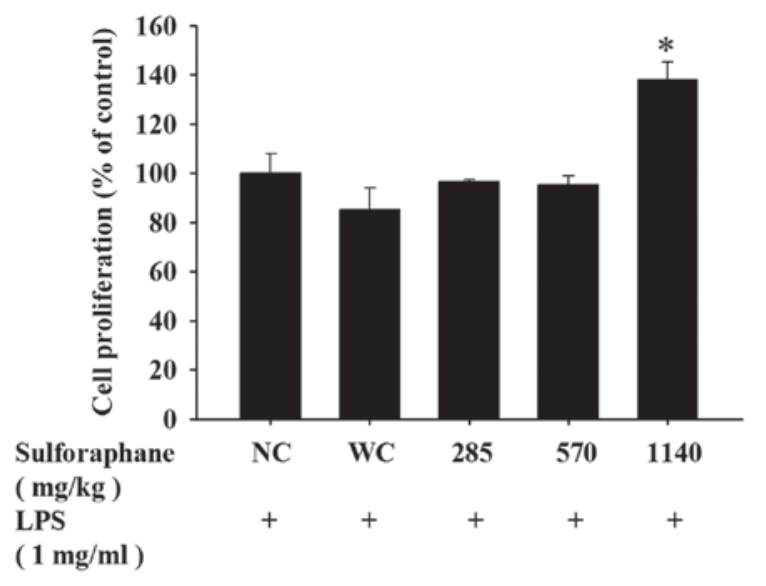

B

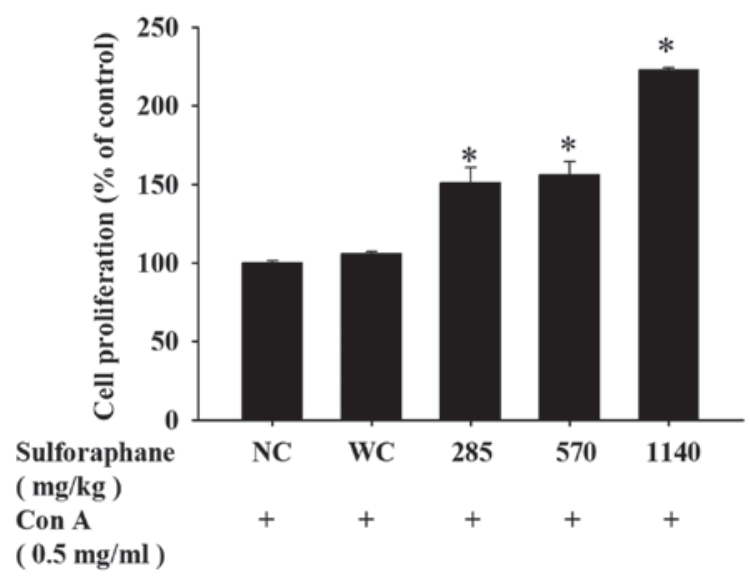

Figure 5. Effect of sulforaphane treatment on the $\mathrm{B}$ and $\mathrm{T}$ cell proliferation in non-leukemic untreated mice, and leukemic untreated, 285,570 or $1140 \mathrm{mg} / \mathrm{kg}$ sulforaphane-treated mice. Isolated $\mathrm{B}$ and $\mathrm{T}$ cells were pretreated with LPS and Con A to assess (A) B and (B) T cell proliferation, respectively. Data are presented as mean \pm standard deviation. ${ }^{*} \mathrm{P}<0.05$ vs WC control group). $\mathrm{NC}$, normal control; WC, WEHI-3-induced leukemia control; LPS, lipopolysaccharide; Con A, concanavalin A.

groups. Furthermore, SFN increased T and B cell markers (Fig. 2A and C), however, had no significant effect on the cell 
markers of monocytes or macrophages (Fig. 2B and D). SFN treatment significantly increased the phagocytotic activity of macrophages from PBMCs (Fig. 3A) and the peritoneal cavity (Fig. 3B). Furthermore, SFN treatment at all concentrations increased $\mathrm{T}$ cell proliferation (Fig. 5B) compared with the control groups, however only $1,140 \mathrm{mg} / \mathrm{kg}$ SFN treatment resulted in an increase in B cell proliferation (Fig. 5A).

In order to protect against invading foreign antigens, numerous white blood cells interact to produce immune responses in humans (1). Clinically, numerous plant-derived bioactive compounds have been used to treat patients with cancer, including paclitaxel from Taxus brevifolia and camptothectin from Camptotheca acuminata (21-24). A previous study demonstrated that SFN induces cell cycle arrest and induces apoptosis, suggesting that it may be a novel therapeutic against leukemia malignancies (17). The antileukemic effect of SFN was demonstrated in blasts from pediatric patients with acute lymphoblastic leukemia (16), however, no sufficient and reliable data exist in literature with regards to the effect of SFN on the immune responses of WEHI-3-induced leukemic mice in vivo. Therefore, in the present study, the effects of SFN treatment on the immune responses of leukemic mice were investigated in vivo.

SFN treatment had no significant effect on the liver and spleen weights, however, $280 \mathrm{mg} / \mathrm{kg}$ treatment significant decreased the body weight of leukemic mice when compared with untreated leukemia mice. The present study demonstrated that SFN promoted a cellular population based on increased cell marker levels, including CD3 ( $\mathrm{T}$ cells) and CD19 (B cells), however, had no significant effect on CD11 (monocytes) populations in leukemic mice. Furthermore, SFN treatment resulted in an increase in the phagocytotic activity of macrophages from PBMC (Fig. 3A) and peritoneal cavity (Fig. 3B), therefore, the function of SFN on the Mac-3 marker and macrophage function requires further research.

As demonstrated in Fig. 4, YAC-1 cells were killed by NK cells following SFN treatment in a dose-dependent manner. SFN treatment $(285,570$ or $1,140 \mathrm{mg} / \mathrm{kg})$ resulted in increased $\mathrm{T}$ cell proliferation following Con A stimulation (Fig. 5B), however only treatment with $1,140 \mathrm{mg} / \mathrm{kg} \mathrm{SFN}$ resulted in increased $\mathrm{B}$ cell proliferation following LPS stimulation (Fig. 5A). Previous studies demonstrated that macrophages serve important roles in innate immunity $(25,26)$, stimulating of NK cell cytotoxicity which may lead the increased immune responses (27). Previous studies demonstrated that cells, including macrophages, $\mathrm{T}$ and $\mathrm{B}$ cells, interact with each other resulting in an immune response $(25,26)$. For example, activated T cells release cytokines promoting the function and activity of macrophages $(25,26)$. Further research is required to assess the immune responses.

In conclusion, the present study suggested that SFN treatment modulated the immune responses through increasing the $\mathrm{T}$ and $\mathrm{B}$ cell markers population, $\mathrm{T}$ and $\mathrm{B}$ cells proliferation, phagocytotic activity of macrophages and increase of NK cell cytotoxicity in leukemic mice in vivo. Whether SFN has a direct antileukemic effect in immune modulations requires further investigation.

\section{Acknowledgements}

The present study was supported by a grant from the China Medical University in Taichung, Taiwan (grant no. CMU102-ASIA-20).

\section{References}

1. Alabsi AM, Ali R, Ideris A, Omar AR, Bejo MH, Yusoff K and Ali AM: Anti-leukemic activity of Newcastle disease virus strains AF2240 and V4-UPM in murine myelomonocytic leukemia in vivo. Leuk Res 36: 634-645, 2012.

2. Dameshek W: Chronic lymphocytic leukemia - an accumulative disease of immunolgically incompetent lymphocytes. Blood 29 (Suppl): 566-584, 1967.

3. Vardiman JW, Thiele J, Arber DA, Brunning RD, Borowitz MJ, Porwit A, Harris NL, Le Beau MM, Hellström-Lindberg E, Tefferi A, et al: The 2008 revision of the World Health Organization (WHO) classification of myeloid neoplasms and acute leukemia: Rationale and important changes. Blood 114: 937-951, 2009.

4. Marshall GM, Dalla Pozza L, Sutton R, Ng A, de Groot-Kruseman HA, van der Velden VH, Venn NC, van den Berg H, de Bont ES, Maarten Egeler R, et al: High-risk childhood acute lymphoblastic leukemia in first remission treated with novel intensive chemotherapy and allogeneic transplantation. Leukemia 27: 1497-1503, 2013.

5. Conaway CC, Wang CX, Pittman B, Yang YM, Schwartz JE, Tian D, McIntee EJ, Hecht SS and Chung FL: Phenethyl isothiocyanate and sulforaphane and their $\mathrm{N}$-acetylcysteine conjugates inhibit malignant progression of lung adenomas induced by tobacco carcinogens in A/J mice. Cancer Res 65: 8548-8557, 2005.

6. Fimognari C, Nüsse M, Berti F, Iori R, Cantelli-Forti G and Hrelia P: Isothiocyanates as novel cytotoxic and cytostatic agents: Molecular pathway on human transformed and non-transformed cells. Biochem Pharmacol 68: 1133-1138, 2004.

7. Trachootham D, Zhou Y, Zhang H, Demizu Y, Chen Z, Pelicano H, Chiao PJ, Achanta G, Arlinghaus RB, Liu J, et al: Selective killing of oncogenically transformed cells through a ROS-mediated mechanism by beta-phenylethyl isothiocyanate. Cancer Cell 10: 241-252, 2006

8. Xu C, Shen G, Yuan X, Kim JH, Gopalkrishnan A, Keum YS, Nair S and Kong AN: ERK and JNK signaling pathways are involved in the regulation of activator protein 1 and cell death elicited by three isothiocyanates in human prostate cancer PC-3 cells. Carcinogenesis 27: 437-445, 2006.

9. Fahey JW, Haristoy X, Dolan PM, Kensler TW, Scholtus I, Stephenson KK, Talalay P and Lozniewski A: Sulforaphane inhibits extracellular, intracellular, and antibiotic-resistant strains of Helicobacter pylori and prevents benzo[a]pyrene-induced stomach tumors. Proc Natl Acad Sci USA 99: 7610-7615, 2002.

10. Zhang Y, Kensler TW, Cho CG, Posner GH and Talalay P: Anticarcinogenic activities of sulforaphane and structurally related synthetic norbornyl isothiocyanates. Proc Natl Acad Sci USA 91: 3147-3150, 1994.

11. Keck AS and Finley JW: Cruciferous vegetables: Cancer protective mechanisms of glucosinolate hydrolysis products and selenium. Integr Cancer Ther 3: 5-12, 2004.

12. Fimognari C, Lenzi M, Sciuscio D, Cantelli-Forti G and Hrelia P: Cell-cycle specificity of sulforaphane-mediated apoptosis in Jurkat T-leukemia cells. In Vivo 21: 377-380, 2007.

13. Choi WY, Choi BT, Lee WH and Choi YH: Sulforaphane generates reactive oxygen species leading to mitochondrial perturbation for apoptosis in human leukemia U937 cells. Biomed Pharmacother 62: 637-644, 2008.

14. Fimognari C, Lenzi M, Cantelli-Forti G and Hrelia P: Induction of differentiation in human promyelocytic cells by the isothiocyanate sulforaphane. In Vivo 22: 317-320, 2008.

15. Moon DO, Kim MO, Kang SH, Choi YH and Kim GY: Sulforaphane suppresses TNF-alpha-mediated activation of NF-kappaB and induces apoptosis through activation of reactive oxygen species-dependent caspase-3. Cancer Lett 274: 132-142, 2009.

16. Suppipat K, Park CS, Shen Y, Zhu X and Lacorazza HD: Sulforaphane induces cell cycle arrest and apoptosis in acute lymphoblastic leukemia cells. PLoS One 7: e51251, 2012. 
17. Fimognari C, Turrini E, Sestili P, Calcabrini C, Carulli G, Fontanelli G, Rousseau M, Cantelli-Forti G and Hrelia P: Antileukemic activity of sulforaphane in primary blasts from patients affected by myelo- and lympho-proliferative disorders and in hypoxic conditions. PLoS One 9: e101991, 2014.

18. Lu HF, Tung WL, Yang JS, Huang FM, Lee CS, Huang YP, Liao WY, Chen YL and Chung JG: In vitro suppression of growth of murine WEHI-3 leukemia cells and in vivo promotion of phagocytosis in a leukemia mice model by indole-3-carbinol. J Agric Food Chem 60 7634-7643, 2012.

19. Yu FS, Yang JS, Yu CS, Chiang JH, Lu CC, Chung HK, Yu CC, Wu CC, Ho HC and Chung JG: Safrole suppresses murine myelomonocytic leukemia WEHI-3 cells in vivo, and stimulates macrophage phagocytosis and natural killer cell cytotoxicity in leukemic mice. Environ Toxicol 28: 601-608, 2013.

20. Lin JJ, Lu KW, Ma YS, Tang NY, Wu PP, Wu CC, Lu HF, Lin JG and Chung JG: Alpha-phellandrene, a natural active monoterpene, influences a murine WEHI-3 leukemia model in vivo by enhancing macrophague phagocytosis and natural killer cell activity. In Vivo 28: 583-588, 2014 .

21. Hattori Y, Satouchi M, Shimada T, Urata Y, Yoneda T, Mori M, Nishimura T, Sunadome H, Kumagai T, Imamura $\mathrm{F}$ et al: A phase 2 study of bevacizumab in combination with carboplatin and paclitaxel in patients with non-squamous non-small-cell lung cancer harboring mutations of epidermal growth factor receptor (EGFR) after failing first-line EGFR-tyrosine kinase inhibitors (HANSHIN Oncology Group 0109). Lung Cancer 87: 136-140, 2015.
22. Lee J, Kim J, Chang E, Choi W, Lee K, Yoon H, Jung S, Park M, Yoon J and Kim S: A Phase II Trial of Neoadjuvant Chemotherapy with Genexol (Paclitaxel) and Epirubicin for Locally Advanced Breast Cancer. J Breast Cancer 17: 344-349, 2014.

23. Otake A, Yoshino K, Ueda Y, Sawada K, Mabuchi S, Kimura T, Kobayashi E, Isobe A, Egawa-Takata T, Matsuzaki S, et al: Usefulness of duloxetine for Paclitaxel-induced peripheral neuropathy treatment in gynecological cancer patients. Anticancer Res 35: 359-363, 2015.

24. Schmid D, Jarvis GE, Fay F, Small DM, Greene MK, Majkut J, Spence S, McLaughlin KM, McCloskey KD, Johnston PG, et al: Nanoencapsulation of ABT-737 and camptothecin enhances their clinical potential through synergistic antitumor effects and reduction of systemic toxicity. Cell Death Dis 5: e1454, 2014.

25. Xie S, Chen M, Yan B, He X, Chen X and Li D: Identification of a role for the PI3K/AKT/mTOR signaling pathway in innate immune cells. PLoS One 9: e94496, 2014.

26. Guleria I and Pollard JW: The trophoblast is a component of the innate immune system during pregnancy. Nat Med 6: 589-593, 2000.

27. Wu Z, Sinzger C, Reichel JJ, Just M and Mertens T: Natural killer cells can inhibit the transmission of human cytomegalovirus in cell culture using mechanisms from innate and adaptive immune response. J Virol 89: 2906-2917, 2015. 